\title{
Integrating mental health into primary health care - Uganda's experience
}

\section{F Kigozi}

Butabika National Psychiatric Referral Hospital/World Psychiatric Association, Zone 14 Representative, Kampala, Uganda

\section{Abstract}

Most developing countries and indeed many African countries have been undertaking reforms of the mental health policies and strategies to improve access and equity for the community to mental health and psychiatric services. This has been in conformity with a health policy philosophy which emphasize decentralization of services to the lower administrative units such as districts, community care as well as integrated delivery of health services within the lower health units. Uganda, one of the developing countries in subSaharan Africa, has been implementing its Health Sector Strategic Plan in which mental health has been identified as a major priority. The guidelines from World Health Organisation (WHO), the Alma Ata Declaration and the subsequent WHO recommendations have provided the guiding philosophy for the implementation of this process. However despite embracing the philosophy and having developed sound policies and implementation programs, practical realities are being experienced on the ground. The need for research and evidence-based approach is urgent to evaluate the success of the programmes, which have been developed by many member countries but whose implementation is still a very slow process.

The paper reviews some of the international recommendations towards availing mental health to the majority of the population and the steps undertaken in implementing the integration approach with a case study for Uganda, points out the challenges and also proposes a way forward.
\end{abstract}

Key words: Policies, Plans, Integration, Primary Health Care, Resources, Uganda.

Received: 10.10 .2005

Accepted: 27.10.2006

\section{Introduction}

Uganda is a landlocked developing country with an estimated population of 24.8 million people according to the Uganda census of 2002 but is now projected at 27 million. ${ }^{1,2}$ About 40 years ago at Independence, Uganda had a prosperous economy with relatively enviable medical services and human resource base in the region. This, however, was destroyed by the successive civil wars and political turmoil which led to the destruction of the economy and to many of the medical personnel leaving the country. The population was thus denied the access to affordable and efficient medical services including mental health care. ${ }^{3}$ The citizens relied on a sparsely distributed health infrastructure especially in rural areas and a highly centralized and bureaucratic mental health

\section{Correspondence:}

Dr Fred Kigozi

Senior Consultant Psychiatrist/ Medical Director, Butabika National

Psychiatric Referral Hospital P.O. Box 7017, Kampala, Uganda

email: buthosp@infocom.co.ug or fredkigozi@yahoo.com infrastructure for a long time in addition to the readily available traditional practitioners all over the country. ${ }^{2,3,4}$

The 2000/200 1, Uganda Demographic and Health Survey (UDHS) and the 2002 Census report revealed several poor demographic and health indicators. ${ }^{1}$ The data showed a high growth rate in excess of $3 \%$ due to a high fertility rate estimated at 7 children per woman. The age structure is young with about half the population below 15 years of age. The Infant Mortality (IMR) was 80 per 1000 live births and Maternal Mortality (MMR) of 50.4 per 10,000 live births. Life expectancy at 43 years and income per capita and GDP of US\$340.00.1

The evolution of psychiatric services in Uganda has followed the trend of devolving responsibility for care from the central large hospital in the capital to regional mental health units and the adoption of community mental health services in an integrated form with all other health care needs including promotive and preventive services such as encouraging good nutrition, attendance of antenatal care, immunisation and discouraging behaviours such as excessive alcohol consumption. ${ }^{5,6,7}$ In addition this encourages the maximum utilization of the few available health workers thereby improving accessibility. 


\section{Health reforms}

In 1999 the government of Uganda (Ministry of Health) developed a ten year (1999-2010) National Health Policy (NHP 1999) and the Health Sector Strategic Plan I (2000/01-2004/05 which has recently been updated to the Health Sector Strategic Plan II (2005/06- 2009/2010).,2,3 The guiding principles in the above documents included Primary Health Care (PHC) as the basic philosophy and strategy for national health development, in line with WHO and Alma-Ata principles. ${ }^{8}$ The National Health Policy (NHP 1999) devolved health services delivery to districts and health sub-districts. It also emphasized a strong collaborative and partnership approach between the public and private sectors, Nongovernmental Organisations (NGOs) and traditional practitioners, while safeguarding the identity of each partner. In this policy, a basic minimum Health Care Package of 12 components was formulated with mental health being a key component to be delivered at all levels of health service delivery. ${ }^{3}$ The Uganda Minimum Health Care Package (UMHCP) on mental health states that to address the heavy and increasing burden of mental illness in the country, the government would promote and support a primary mental health programme supported by appropriate referral services at the regional and national levels. ${ }^{3}$

\section{Mental Health Programme and Services}

The decentralisation and integration of Mental health care has taken place in an environment characterized by; the usual burden of traditional psychiatric disorders, poverty related stress, the continued civil wars in the North and North-eastern parts of the country with the associated high prevalence rates of post-traumatic disorders, and the psychosocial effects of the HIV/AIDS pandemic in the country. ${ }^{9}$

In the context of the above environment, mental health services have been fully decentralized and the process of integration of mental care into the general health care is underway. The results so far has been a structure that promotes equity and access by the population to a basic mental health service that includes treatment, promotive, preventive and rehabilitative services. This process encourages orderly referrals from Health Centre ( $\mathrm{HCl}$ ) (village level), through $\mathrm{HC}$ II (Parish) HC III (Sub-country), HC IV (Country) to district hospitals, Regional Referral Hospitals up to the National Referral and Teaching Hospital in the Capital. Thus, at the lower levels up to the district hospital, the clients with minor mental ailments are generally managed together in an integrated way with the other patients suffering from general physical ailments both at Outpatient and Inpatient facilities.

\section{Challenges facing integration}

It is currently an established fact, that the de-institutionalization of the mentally ill has partly been driven by humanitarian impulses with a global influence and partly by financial necessity as well as advances in our knowledge of the spectrum of mental disorders and the discovery of new and effective therapeutic interventions. ${ }^{10}$ The realization that basic medical services including mental health care were not reaching much of the rural population dictated the policy to look for alternatives in primary health care concept as a way of providing basic mental health services. Construction of new large mental hospitals was stopped and instead small mental health units built within regional hospitals to provide referral needs in the integrated care system for lower health units. ${ }^{6}$ These changes, however, have created new human resource challenges that have included, a need for the few available specialists to take on new roles and responsibilities for which they were not trained, lack of skills in the general health worker to provide mental health care and a critical shortage of mental health professionals to manage the expanded mental health units. In addition there has been an obvious paucity of research data to guide policy development, planning and implementation. The pace at which the above changes have occurred has varied from district to district depending on the commitment of the key players on the ground. Reasons for the inertia include poor prioritization of mental health activities which determines the budgetary allocation and the resistance to change.

\section{Process of integration}

To effectively implement the integration of mental health into general health care services key activities have been undertaken following the identification of the above challenges. Major activities have included; policy and legislation reforms, review of psychiatric education and curricula, development of guidelines and monitoring tools, provision of psychotropic drugs and other therapies, public education and consumer empowerment. ${ }^{7}$

\section{Policy and Mental Health Legislation Reforms}

This was key and required urgent attention. The policy on integration was entrenched in all Ministry of Health policy documents including the Strategic plan which is the basis for resource allocation. The Committee to reform mental health legislation was set up and this dealt with the relevant sections of the law such as those dealing with hospitalization and community care to enable many other health institutions provide the inpatient facilities in an integrated form.

\section{Psychiatric Education and Continuing Medical Education (CME)}

This has been a vital activity in the implementation of the programme to equip district health workers with update knowledge and skills to handle mental health care as planned. There has been massive training and re-training of district health workers. Equally urgent, was the need to review general nurses and clinical officers' curricula to include adequate content so as to enable the products of such vital Post-basic health training institutions, pass out professionals adequately prepared to face the new challenges. The curriculum for undergraduate medical students was also reviewed. The clerkship programme has been enriched with more community component and compulsory university examinations. Regular district and central training workshops for qualified general staff have been ongoing on a regular basis. The course content equips the participants with the skills to manage basic mental disorders in the community and lower level health units with the capacity to refer to the next level all complicated clients with mental disorders.

\section{Developing Guidelines and Monitoring Tools}

As part of implementation of the integration strategy, the centre developed guidelines, training manuals and monitoring tools with a multisectoral team including major stakeholders such as the 
University Departments of Psychiatry, National Referral Mental Hospital and selected Non Government Organisations (NGOs). In addition, support supervision teams regularly move out to the districts to monitor the implementation process, facilitate local training and clinical support to the health units' staff on selected difficult cases in the community.

\section{Provision of Psychotropic Drugs and Other Therapeutic} Interventions

The usual drug procurement system was strengthened with a special project. This less bureaucratic support has ensured a regular flow of drugs for most of the essential items. In addition, it has given further confidence to the clients particularly those with recurring chronic mental disorders who are now assured of getting their regular supply within their communities.

Furthermore, the constant supply of psychotropic drugs to the lower health units resulted into a real demand for mental health services with ever increasing number of patients voluntarily turning up for help. The challenge will be to ensure sustainability of adequate drug supply.

\section{Public Education and Consumer Empowerment}

Working in partnership with several local and international NGOs, the Mental Health Division has aggressively carried out mass education of the public as part of the integration process. The emphasis in most of the messages has been to clearly demonstrate that mental health disorders are not very different from general physical problems. Information on causes, symptoms and available treatment modalities is continuously being disseminated. Major social events and celebrated international events such as World Health and Mental Health Days have also provided opportunity to send out critical messages on promotion, prevention, causes, symptoms of mental illness and the treatment options available at the various levels of health care.

Leaflets, brochures and posters have been developed and are regularly supplied out to offer further information on mental health and related problems emphasizing early care in any local or nearby health unit as soon as symptoms of mental disorders begin to show. Using the same systems, the vicious cycle of stigma against mental disorders and their discrimination has been tackled during the integration strategy by aggressively disseminating messages as indicated above. Interestingly, the process of handling mental health related problems side by side in most health units is by itself creating harmony and reduction of inherent fears within the populations.

\section{Conclusion}

There is now almost universal recognition that primary care is the place where the majority of the mentally distressed people first present for help and also an acceptance that even in physical disorders the psychological effect require urgent attention in the same setting. In Uganda the health reforms which included major steps in implementing the decentralization of health and integration process as explained above, has resulted in new physical structures being constructed at regional hospitals, curriculum changes for various cadres of health workers, improved knowledge and skills in the promotion of mental health, and care of the mental ill, improved budgetary support for mental health activities, the availability of psychotropic medications at the various health centre levels and reduced stigma.

The experience in Uganda demonstrates that the integration of mental health into general care as part of primary health care ensures equity and access to affordable mental health care under resource constraints. Furthermore, the strategy leads to enhanced resource mobilization for mental health within the system through shared benefits and a holistic approach to patient's care. 11 Research into best practice and to demonstrate successes in the process must be intensified.

\section{References:}

1. Ministry of Finance, Planning and Economic Development Uganda (MOFPED). Uganda Demographic and Health Survey; MOFPED, 2002.

2. Ministry of Health of Uganda. Health Sector Strategic Plan II 2005/062009/10 (HSSP II). Ministry of Health, 2005.

3. Ministry of Health of Uganda. National Health Policy (NHP). Ministry of Health, 1999.

4. Ministry of Health of Uganda. Health Sector Strategic Plan I 2000/012004/05 (HSSP) Ministry of Health, Uganda Kampala, 2000.

5. Ministry of Health of Uganda. The National Mental Health Programme. Ministry of Health, Uganda, 1996.

6. Breakey WR. The rise and fall of the state hospital. In: Breakey WR, ed, Integrated mental health services. New York: Oxford University Press Inc, 1996.

7. Kigozi F, Kinyanda E, Basangwa D. Mental health services in Africa. In: Njenga FC, Acuda W, Patel V, Maj M eds, Essentials of Clinical Psychiatry for sub-Saharan Africa. Milano: Masson, 2005: 230-236.

8. World Health Organisation. Declaration of Alma Ata. World Health Organisation, 1978.

9. Kigozi F, Kinyanda E, Kasirye R. A product and the high risk group of HIVIAIDS. Southern African Journal of Child and Adolescent Mental Health, 1999; 2: 2.

10. Goldberg DP. Psychiatry and Primary Care: World Psychiatry 2003; 2 (3): 153-157.

11. Ministry of Health, Uganda. In: Information Discovery and Solutions Limited, eds. Report of the Baseline Survey, to provide basic data for the development of the National Communication Strategy, for the promotion of the National Minimum Health Care Package (NMHCP). Kampala: Ministry of Health, 2004: 108-132. 